\title{
Normal Echocardiographic Parameters of Healthy Adult Individuals working in National Heart Centre
}

\author{
Prajapati $D^{1}$, Sharma $D^{1}$, Baidya S.G ${ }^{1}$, Shakya $U^{1}$, Shrestha $N^{1}$ \\ ${ }^{1}$ Department of Cardiology, Shahid Gangalal National Heart Centre, Bansbari, Kathmandu, Nepal
}

\begin{abstract}
Background

Studies evaluating potential differences in normal cardiac dimensions and body mass indices of various ethnic populations using $2 \mathrm{D}$ echocardiography have reported variations based on gender and ethnicity. Currently, accepted echocardiographic reference values are from US studies, and the limited information is available on Nepalese population. The purpose of this study was to derive population-based reference values for two-dimensional (2D) guided M-mode echocardiographic dimensions and left ventricular mass of adult Nepalese that can be applied in epidemiologic studies, clinical trials and clinical practice.
\end{abstract}

\section{Methods}

97 individuals were randomly selected, out of 502 staffs working in our hospital, who were over 18 years of age and were free of cardiovascular disease. Subjects underwent M-mode and 2D echocardiogram with color Doppler study. Reference values were derived for end-diastolic and end-systolic left ventricular internal dimensions, left ventricular wall thickness, left atrial dimension, aorta, LV mass. Measurements were described by mean, standard deviation and $95 \%$ reference range.

Results

Echocardiographic measurements were within standard normal limits. The measurements of aorta, left atrium, interventricular septum, left ventricle in systole and diastole, left posterior wall and left ventricular mass, adjusted or not for body surface area, were significantly higher in males. Several echocardiographic measurements, adjusted or not for anthropometric measurements, had different mean and range than the reference limits in US-based studies.

\section{Conclusion}

The means and range for the measurements of left atrium volume, left ventricular diastolic dimension and left ventricular mass found in this survey were lower than those indicated by the international literature and accepted as normal limits. The results of this study strongly indicate the need for a larger scale study to further establish ethnic-specific and gender-specific echocardiographic reference values for the Nepalese population.

Keyword Echocardiography, cardiac dimensions, National Heart Centre. 


\section{Background}

All the Echocardiographic reference parameters that we use to compare during Echocardiographic studies are derived from those defined in the western world. We till date do not have a proper reference range based on studies conducted in Nepal or South Asia itself. It is a well knonwn fact that that the population in south asia has a very much different genetic and physical make up as compared to the population in the west. The difference in the body size in itself brings into question the reference range that we quote as normal values derived from studies conducted in the west. We have thus made an effort to study an healthy adult population in Nepal, beginning with a pilot study enrolling staff members of the National Heart Centre for recording normal echocardiographic parameters.

\section{MATERIALS AND METHODS}

\section{Study samples}

For our study, 126 apparently healthy subjects were randomly selected from the total of 362 Staffs of Shahid Gangalal National Heart Centre and 140 Outsourced staffs working in the hospital. Out of these subjects, 29 subjects were excluded due to evidence of heart disease or other systemic disease. Among them, 15 had Hypertension, 4 subjects had Rheumatic Heart Disease, 6 had poor echo window and 4 had diabetes mellitus.

Ninety seven normal subjects consisted of 50 males and 47 females. Their ages ranged from 18 to 52 years in men and women (mean $\pm S D, 27.9 \pm 6.6$ years in men and 28.7 \pm 6.7 years in women).

\section{Study Parameters}

Baseline measurements included measurements of blood pressure, weight (kilograms); height (centimeters) and body surface area (BSA) were calculated using the Mosteller formula ${ }^{1}$.

Two-dimensionally and M-mode, ECG guided, echocardiograms were recorded using available equipments VIVID 7 (General Electric Company) and IE33 (Philips Company) instruments, with 1.5-4.0 MHz transducer. $\mathrm{M}$-mode recordings of the left ventricle were obtained with the subject in the supine and left lateral decubitus position. Measurements on the echocardiograms were obtained according to the recommendations of the American Society of Echocardiography ${ }^{2}$. The internal dimensions of the left ventricle at end diastole were measured at the onset of the QRS complex. The thickness of the ventricular septum and posterior wall were measured in the same portion of the record used to measure the left ventricular internal dimensions. Two measurements were made and average values were taken.

Left ventricular mass was calculated using the formula from Devereux et al. ${ }^{3,4}$

Global left ventricular function was assessed from 2D-echocardiography images and any patient showing segmental hypokinesia, valvular heart disease, or myocardial hypertrophy was excluded.

Aorta, left atrium, interventricular septum, and posterior wall thickness, left ventricle in systole and diastole, and the right ventricle were evaluated. The beginning of the QRS complex (first deflection) was used as the area to obtain the measurements at the end of diastole and maximal incursion of the septal movement for the measurements of the systolic dimension of the left ventricle. The cavity and wall thicknesses were measured at the level of the chordae of the mitral valves.

\section{Statistical methods}

The parameters in our study were described as means and standard deviation. The analyses were done in the entire sample and stratified by gender. We present the $P$ values, assuming statistical significance of $P$ less than 0.05 and 0.001 .

Reference ranges for each measurement were calculated using $95 \%$ reference range (mean \pm 2 standard deviation).

\section{Results}

The characteristics of the study population of 47 women and 50 men are summarized in Table 1.

Table 1: Characteristics of the individuals studied stratified by gender

\begin{tabular}{|c|c|c|c|c|c|}
\hline & \multicolumn{2}{|c|}{ Male $(n=50)$} & \multicolumn{2}{|c|}{ Female ( $n=47)$} & \multirow[t]{2}{*}{ P Value } \\
\hline & Mean & SD & Mean & SD & \\
\hline Age (year) & 27.9 & 6.6 & 28.7 & 6.7 & 0.546 \\
\hline Height (m) & 1.69 & 0.07 & 1.53 & 0.06 & $<0.001$ \\
\hline Weight (Kg) & 62.77 & 9.7 & 54.62 & 10.4 & $<0.001$ \\
\hline $\begin{array}{l}\text { Body Mass Index (Kg/ } \\
\left.\mathrm{m}^{2}\right)\end{array}$ & 21.80 & 3.45 & 23.32 & 4.15 & 0.52 \\
\hline Body Surface Area $\left(\mathrm{m}^{2}\right)$ & 1.71 & 0.14 & 1.51 & 0.15 & $<0.001$ \\
\hline HR (bpm) & 75.3 & 13.3 & 80.0 & 12.0 & 0.69 \\
\hline $\begin{array}{l}\text { Systolic Blood Pressure } \\
(\mathrm{mmHg})\end{array}$ & 114.4 & 10.5 & 105.3 & 12.1 & $<0.001$ \\
\hline $\begin{array}{l}\text { Diastolic Blood } \\
\text { Pressure }(\mathrm{mmHg})\end{array}$ & 75.8 & 8.8 & 66.8 & 9.3 & $<0.001$ \\
\hline
\end{tabular}

Age, body mass index, and heart rate were similar in men and women. Height, body surface area, weight, the systolic and diastolic blood pressure was significantly higher in men. 
The echocardiographic measurements are presented, according to gender, in table 2 , including the values for left ventricular mass corrected by the body surface area.

Table 2: Echocardiographic measurements in men and women

\begin{tabular}{|c|c|c|c|c|c|}
\hline & \multicolumn{2}{|c|}{ Male $(n=50)$} & \multicolumn{2}{|c|}{ Female $(n=47)$} & \multirow{2}{*}{ P Value } \\
\hline & Mean & SD & Mean & SD & \\
\hline $\begin{array}{l}\text { LV Diastolic dimension } \\
(\mathrm{mm})\end{array}$ & 47.5 & 4.3 & 43.4 & 4.1 & $<0.001$ \\
\hline $\begin{array}{l}\text { LV systolic dimension } \\
(\mathrm{mm})\end{array}$ & 29.2 & 3.9 & 27.2 & 3.4 & 0.009 \\
\hline $\begin{array}{l}\text { LV Posterior Wall } \\
\text { Thickness (mm) }\end{array}$ & 9.4 & 1.1 & 8.3 & 1.2 & $<0.001$ \\
\hline $\begin{array}{l}\text { IV Septum Thickness } \\
(\mathrm{mm})\end{array}$ & 9.6 & 1.1 & 8.3 & 1.1 & $<0.001$ \\
\hline LA Dimension (mm) & 35.0 & 2.9 & 32.8 & 3.9 & 0.002 \\
\hline $\operatorname{ACS}(\mathrm{mm})$ & 15.6 & 2.7 & 16.3 & 2.2 & 0.175 \\
\hline Aortic Root (mm) & 27.5 & 3.0 & 26.0 & 3.1 & 0.015 \\
\hline Ascending Aorta (mm) & 17.6 & 3.7 & 15.1 & 2.5 & $<0.001$ \\
\hline RV (Diastole, mm) & 17.6 & 3.3 & 19.5 & 3.5 & 0.009 \\
\hline LV Mass (g) & 158.32 & 27.93 & 115.55 & 2.91 & $<0.001$ \\
\hline LV Mass/BSA $\left(\mathrm{g} / \mathrm{m}^{2}\right)$ & 92.39 & 15.01 & 75.85 & 15.77 & $<0.001$ \\
\hline LA Volume (ml) & 31.71 & 8.88 & 28.03 & 8.93 & 0.045 \\
\hline $\mathrm{EF}(\%)$ & 68.68 & 6.03 & 67.12 & 6.03 & 0.206 \\
\hline
\end{tabular}

The dimensions of the aorta, left atrium, interventricular septum, left ventricle in systole and diastole, posterior wall, and left ventricular mass, corrected or not, were significantly higher in men.
The $95 \%$ reference range of the echocardiographic parameters calculated as mean \pm 2 standard deviation, are presented in table 3.

Table 3: $95 \%$ Reference Range of the measured parameters

\begin{tabular}{lcccc} 
& \multicolumn{2}{c}{ Male $(\mathrm{n}=50)$} & \multicolumn{2}{c}{ Female $(\mathrm{n}=47)$} \\
\cline { 2 - 5 } & $\begin{array}{c}\text { Lower } \\
\text { Limit }\end{array}$ & $\begin{array}{c}\text { Upper } \\
\text { Limit }\end{array}$ & $\begin{array}{c}\text { Lower } \\
\text { Limit }\end{array}$ & $\begin{array}{c}\text { Upper } \\
\text { Limit }\end{array}$ \\
\hline LVDiastolic dimension (mm) & 38.9 & 56.1 & 35.2 & 51.6 \\
\hline LV systolic dimension (mm) & 21.4 & 37 & 20.4 & 34 \\
\hline LV Posterior Wall Thickness & 7.2 & 11.6 & 5.9 & 10.7 \\
(mm) & 7.4 & 11.8 & 6.1 & 10.5 \\
\hline IV Septum Thickness (mm) & 29.2 & 40.8 & 25 & 40.6 \\
\hline LA Dimension (mm) & 10.2 & 21 & 11.9 & 20.7 \\
\hline ACS (mm) & 21.5 & 33.5 & 19.8 & 32.2 \\
\hline Aortic Root (mm) & 10.2 & 25 & 10.1 & 20.1 \\
\hline Ascending Aorta (mm) & 11 & 24.2 & 12.5 & 26.5 \\
\hline RV (Diastole, mm) & 102.46 & 214.18 & 109.73 & 121.37 \\
\hline LV Mass (g) & 62.37 & 122.41 & 44.31 & 107.39 \\
\hline LV Mass/BSA (g/m ${ }^{2}$ ) & 13.95 & 49.47 & 10.17 & 45.89 \\
\hline LA Volume (ml) & 56.62 & 80.74 & 55.06 & 79.18 \\
\hline EF (\%) & & & &
\end{tabular}

The values of flow velocity and flow gradient across respective valves in our study is presented in the tables 4 and 5 respectively.

Table 4: Flow Velocity across respective valves

\begin{tabular}{lcccc} 
& \multicolumn{2}{c}{ Male (=50) } & & Female (=47) \\
\hline & Mean & SD & Mean & SD \\
\hline Mitral Inflow E (m/s) & 0.90610 & 0.205043 & 1.06209 & 1.104836 \\
\hline Mitral Inflow A (m/s) & 0.56716 & 0.115506 & 0.70651 & 0.948655 \\
\hline Mitral Inflow Mean (m/s) & 0.3875 & 0.07559 & 0.6101 & 0.76596 \\
\hline Mitral Inflow (E/A) & 1.6492 & 0.424 & 1.6386 & 0.05715 \\
\hline Aortic Valve Peak (m/s) & 1.1376 & 0.234132 & 1.33738 & 1.352025 \\
\hline Aortic Valve Mean (m/s) & 0.63674 & 0.116967 & 0.78385 & 0.717203 \\
\hline Tricuspid Valve Peak (m/s) & 0.66934 & 0.149623 & 0.74651 & 0.737558 \\
\hline Tricuspid Valve Mean (m/s) & 0.4351 & 0.108847 & 0.50617 & 0.547763 \\
\hline Pulmonary Valve Peak (m/s) & 0.93166 & 0.12127 & 1.01562 & 1.021901 \\
\hline PulmonaryValve Mean (m/s) & 0.55180 & 0.072790 & 0.65423 & 0.684833
\end{tabular}

Table 5: Flow Gradient across respective valves

\begin{tabular}{|c|c|c|c|c|}
\hline & \multicolumn{2}{|c|}{ Male $(=50)$} & \multicolumn{2}{|c|}{ Female (=47) } \\
\hline & Mean & SD & Mean & SD \\
\hline Mitral Inflow E (mmHg) & 3.37 & 1.202 & 3.38 & 1.236 \\
\hline Mitral Inflow A (mmHg) & 1.32 & 0.587 & 1.52 & 0.789 \\
\hline Mitral Inflow Mean (mmHg) & 0.87 & 0.244 & 1.15 & 0.466 \\
\hline Aortic Valve Peak (mmHg) & 5.47 & 1.577 & 5.30 & 2.062 \\
\hline
\end{tabular}




\section{Nepalese Heart Journal}

\begin{tabular}{|llllll|}
\hline Aortic Valve Mean $(\mathrm{mmHg})$ & 2.24 & 0.693 & 2.36 & 0.923 \\
\hline Tricuspid Valve Peak $(\mathrm{mmHg})$ & 1.87 & 0.835 & 1.79 & 0.800 \\
\hline Tricuspid Valve Mean $(\mathrm{mmHg})$ & 0.87 & 0.478 & 0.97 & 0.450 \\
\hline Pulmonary Valve Peak $(\mathrm{mmHg})$ & 3.52 & 0.933 & 3.21 & 1.290 \\
\hline Pulmonary Valve Mean $(\mathrm{mmHg})$ & 1.49 & 0.428 & 1.50 & 0.583 \\
\hline
\end{tabular}

The velocity of individual segments determined with tissue Doppler echocardiography is presented in table 6.

Table 6: Flow Velocity of individual segments determined with Tissue Doppler Echocardiography

\begin{tabular}{|lcccc} 
& & Male (=50) & Female (=47) & Mean \\
\hline Basal Septum S & Mean & SD & 0.082974 \\
\hline Basal Septum E' & 0.091144 & 0.140305 & 0.34602 & 0151679 \\
\hline Basal Septum A' & 0.12611 & 0.024261 & 0.07426 & 0.022445 \\
\hline Basal Lateral S & 0.08469 & 0.023595 & 0.102664 \\
\hline Basal Lateral E' & 0.115406 & 0.0316423 & 0.15266 \\
\hline Basal Lateral A' & 0.20114 & 0.143907 & 0.035484 & 0.07990 \\
\hline
\end{tabular}

\section{Discussion}

Generally, reference range in different ethnic groups is slightly different ${ }^{5}$. Average height, weight, BMI and BSA are less in Nepalese than in western population. The smaller physique of Asians may highlight the potential need to assess the validity of using separate cardiac reference data for this ethnic group. In Nepal, clinicians are using reference range for echocardiographic values from western literature and books. In clinical practice, it has been long felt that reference range from western data cannot be fully applied in our scenario.

The primary and derived echocardiographic parameters in men and women in the Nepalese population differ significantly from each other. In this study, it has been found that the reference range of most echocardiographic parameters are slightly different as compared with those used in the western studies and are similar to those found in Asian countries.

We plan to conduct a larger population based study to establish the reference range of echocardiographic parameters in Nepalese population. This pilot study is the infant step in this direction.

\section{Study limitation}

This study is small study consisting of randomized populations of people working in Shahid Gangalal National Heart Centre and the study population cannot be the representation of whole Nepalese population. Relatively young patients were the subjects in this study and the sample size was also small.

\section{References}

1. Mosteller RD. "Simplified calculation of body-surface area". N Engl J Med 1987; 317:1098. PMID 3657876

2. Lang RM, Bierig M, Devereux RB, et al: Recommendations for chamber quantification. J Am Soc Echocardiogr 2005; 18:1440-1463.

3. Devereux R, Alonso D, Lutas E, et al: Echocardiographic assessment of left ventricular hypertrophy: comparison with necropsy findings. Am J Cardiol 1986; 57:450-458.

4. Devereux RB, Roman MJ: Evaluation of cardiac and vascular structure by echocardiography and other noninvasive techniques, in Laragh JH, Brenner BM (eds): Hypertension: Pathophysiology, Diagnosis, Treatment. 2nd ed. New York, Raven, 1995, pp 1969-1985.

5. Schvartzman PR, Fuchs FD, Mello AG, et al: Normal values of echocardiographic measurements: a populationbased study. Arq Bras Cariol 2000;75:111-114.

6. Camacho RB, Esquivel AJG, Ferez SS, et al: Normal values in Mexico of the echocardiographic measurements of the left heart. Arch Inst Cardiol Mex 1988;58:127-135.

7. Trivedi SK, Gupta OP, Jain AP, et al: Left ventricular m-mode echocardiographic measurements of Indian population. J Assoc Physicians India 1993;41:14-16.

8. Nancy K. W. Leung, MASc, RDCS, RDMS, MRT R: Echocardiographic Values for Cardiac Dimensions and Left Ventricular Mass of Normal Chinese Adults A Pilot Study. JDMS 2009;25:300-309 